OPEN ACCESS

Edited by:

Paula Casati,

Consejo Nacional de Investigaciones Científicas y Técnicas (CONICET),

Argentina

Reviewed by:

Raquel Esteban,

University of the Basque Country

(UPV/EHU), Spain

Nejat Duzgunes,

University of the Pacific, United States

*Correspondence:

Catherine Riou

catherine.riou@unilim.fr

Specialty section:

This article was submitted to

Plant Abiotic Stress,

a section of the journal

Frontiers in Plant Science

Received: 13 February 2018

Accepted: 03 May 2018

Published: 23 May 2018

Citation:

Issawi M, Sol V and Riou C (2018) Plant Photodynamic Stress: What's

New? Front. Plant Sci. 9:681

doi: 10.3389/fpls.2018.00681

\section{Plant Photodynamic Stress: What's New?}

\author{
Mohammad Issawi, Vincent Sol and Catherine Riou* \\ Laboratoire Peirene (EA7500), Faculté des Sciences et Techniques, Université de Limoges, Limoges, France
}

In the 1970's, an unconventional stressful photodynamic treatment applied to plants was investigated in two directions. Exogenous photosensitizer treatment underlies direct photodynamic stress while treatment mediating endogenous photosensitizer over-accumulation pinpoints indirect photodynamic stress. For indirect photodynamic treatment, tetrapyrrole biosynthesis pathway was deregulated by 5 -aminolevulenic acid or diphenyl ether. Overall, photodynamic stress involves the generation of high amount of reactive oxygen species leading to plant cell death. All these investigations were mainly performed to gain insight into new herbicide development but they were rapidly given up or limited due to the harmfulness of diphenyl ether and the high cost of 5-aminolevulinic acid treatment. Twenty years ago, plant photodynamic stress came back by way of crop transgenesis where for example protoporphyrin oxidases from human or bacteria were overexpressed. Such plants grew without dramatic effects of photodamage suggesting that plants tolerated induced photodynamic stress. In this review, we shed light on the occurrence of plant photodynamic stress and discuss challenging issues in the context of agriculture focusing on direct photodynamic modality. Indeed, we highlighted applications of exogenous PS especially porphyrins on plants, to further develop an emerged antimicrobial photodynamic treatment that could be a new strategy to kill plant pathogens without disturbing plant growth.

Keywords: 5-aminolevulinic acid, diphenyl ether herbicides, photosensitizers, plant photodynamic stress, porphyrins, tetrapyrroles

\section{INTRODUCTION}

Almost all abiotic stresses induce oxidative stress underlying imbalance between reactive oxygen species (ROS) production and plant defense systems (Ramel et al., 2012; Müller-Xing et al., 2014; Hu et al., 2015; Loreti et al., 2016; Vian et al., 2016; Chakradhar et al., 2017; Hasan et al., 2017; Jaleel et al., 2017; Ohama et al., 2017; Rihan et al., 2017; Yang and Guo, 2017). Often, photooxidative and photodynamic stresses are confused whereas they bear two distinct meanings. The former points out a light-driven generation of ROS in chloroplasts through the photosensitization of excited chlorophyll molecules that are embedded in antennae complex and reaction center or via electron leakage from overloaded electron transport chain within photosystem apparatus. However, photodynamic stress involves the accumulation of exogenous or endogenous PS at various subcellular compartments and subsequently photochemical ROS production via two types of photochemical reactions under light conditions. In the type I, redox state change of excited sensitizer occurs upon reactions with biological molecules and oxygen resulting in hydrogen peroxide and free radical generation while In the Type II, energy from excited PS is transferred directly to oxygen leading to singlet oxygen production (Figure 1; Foyer et al., 1994; Pospíšil, 2016; Kashef et al., 2017). 
In plants, occurrence of photodynamic stress corresponds to two distinct artificial situations. The first one involves deregulations of plant tetrapyrrole biosynthetic pathway using molecules such as 5-aminolevulinic acid (ALA), diphenyl ether (DPE) or genetic tools. Tetrapyrroles play numerous roles from light harvesting, oxygen transport, oxidative phosphorylation, oxygen storage, nitrogen fixation to ROS scavenging (heme) (Figure 1A; Battersby et al., 1980; Senge et al., 2014, 2015). Under normal conditions, this primary biosynthetic pathway is tiny regulated and mainly confined to plastidial organelles that protect cells from potential or accidental oxidative burst. Nevertheless, when this pathway is not anymore regulated by for instance exogenous supply of ALA or DPE or genetic modifications, some intermediates such as protoporphyrin IX (PPIX) and Mg-porphyrins become powerful photosensitizers that could trigger carbohydrates, proteins, lipids and nucleic acids damages (Rebeiz, 2014). In the second situation, photodynamic stress is induced through plant exposure to exogenous PS which are able to produce high amount of ROS inside cells under irradiation. Applications of exogenous PS such as phenothiazinium dyes, coumarins and furocoumarins, porphyrins were performed and summarized in Table 1. A new application of photodynamic treatment on plants is raising up as efficient weapon to struggle against pathogens essentially bacteria and fungi in the context of the so-called antimicrobial photodynamic treatment (APDT) (Figure 1B). Indeed, within APDT, plants of agronomic interest will normally grow protecting themselves from deleterious effect of photoactivated PS via setting up powerful antioxidant machinery. This review will develop photodynamic stress in plants and focus on the direct photodynamic stress regarding APDT to gain insight in improving agronomic practices with high crop yield and environmental protection goals. Photodynamic strategy applied to pathogens or microorganisms is subject of numerous reviews and will not be developed here (Ben Amor and Jori, 2000; Jori and Brown, 2004; Maisch, 2007, 2009; Donnelly et al., 2008; Almeida et al., 2011; Jori, 2011; Alves et al., 2015; Liu et al., 2015; Tim, 2015; Hamblin, 2016; Wainwright et al., 2016; Kashef et al., 2017).

\section{INDIRECT PHOTODYNAMIC STRESS}

Forcing plants to accumulate excessive amount of endogenous tetrapyrrolic photosensitizers induce photodynamic stress conditions such as ALA feeding, DPE treatment as well as by transgenesis experiments leading to growth and development impediment. In this review, we will not develop the crop transgenesis tools because they do not fit with plant photodynamic treatment. The reader should refer to theses references for more informations (Li, 2003; Lee et al., 2004; Li and Nicholl, 2005; Jung et al., 2008; Ayliffe et al., 2009; Jung, 2011; Quesada et al., 2013; Yun et al., 2013; Kim et al., 2014).

\section{5-aminolevulinic Acid (ALA) Feeding}

5 -aminolevulinic acid is not a PS per se. Instead, it is a non-protein amino acid and the first common precursor of the tetrapyrrole (chlorophylls, heme, and derivatives) pathway
(Figure 1A). Its supply lead to PPIX and/or other intermediates over-accumulation. From the 70's, exogenous application of ALA on yeast, insects, plants and in mammal cells was shown to induce high accumulation of tetrapyrroles (Figure 1A; Brouillet et al., 1975; Rebeiz et al., 1984, 1995; Matsumoto et al., 1994; Juzeniene et al., 2002; Fotinos et al., 2006; $\mathrm{Xu}$ et al., 2015). When tetrapyrroles were over-accumulated by ALA feeding, plants could not anymore struggle against induced photodynamic stress and died (Rebeiz et al., 1984, 1990; Matsumoto et al., 1994). When cucumber fields were sprayed with ALA, it was found that seedlings accumulated massive amount of endogenous porphyrins especially the potential singlet oxygen generator "protochlorophyllide" under 5,000 foot candle (Rebeiz et al., 1988). A similar result was obtained on duckweed (Lemna paucicostata Hegelm.) that showed rapid membrane damage after light irradiation and increase in both protochlorophyllide and PPIX contents suggesting herbicidal effect of ALA (Matsumoto et al., 1994). In the other hand, ALA-treated plants significantly upregulated transcript levels of genes encoding superoxide dismutase and serine/threonine kinase receptors but the induction of antioxidative components lacked capacity to withstand ROS generation (Phung and Jung, 2014, 2015). In 2004, Jung and co-workers shed light on "photodynamic stress" as they showed that rice plants suffered from severe oxidative damage upon the ectopic expression of the bacterial ALA synthase gene bringing about the accumulation of harmful photosensitizers PPIX and protochlorophyllide under $350 \mu \mathrm{mol} . \mathrm{m}^{-2} \cdot \mathrm{s}^{-1}$ (Jung et al., 2004). ALA feeding was performed in order to look for a new herbicide. However, there was no commercial formulation of ALA as field effective herbicide owing to the high amount required $(\geq 5 \mathrm{mM})$ and the cost-effective treatment (Sasikala et al., 1994; Phung and Jung, 2014; Xu et al., 2015; Nguyen et al., 2016).

\section{Diphenyl Ether (DPE) Treatment}

Since 1960's, DPE essentially oxyfluorfen and acifluorfen were introduced as commercial herbicides to control weeds (Yang et al., 2006). They constitute the main class of PPO-inhibiting herbicides that are widely investigated. Phung and Jung (2015) reported the different responses of photodynamically stressed rice plants undergoing ALA $(5 \mathrm{mM})$ and oxyfluorfen $(50 \mu \mathrm{M})$ herbicidal treatment. In term of phenotype under illumination, ALA induced bleached necrotic spots while oxyfluorfen caused bronzed necrotic spots on the leaves. This difference in photodynamic symptoms was due to PPIX overaccumulation in cytoplasm in DPE-treated plants whereas the photodynamic destruction of chlorophyll by $\mathrm{Mg}$-porphyrins was responsible of the white spot appearance. Beyond the phenotypical effects, the brown necrosis in DPE-treated plants exhibited a more dispersed $\mathrm{H}_{2} \mathrm{O}_{2}$ production and was accompanied by an increase in $\mathrm{H}_{2} \mathrm{O}_{2}$-scavenging enzymes, catalase and peroxidase activities as well as dehydroascorbate content, a strong stress marker compared to those of ALA-treated plants (Phung and Jung, 2015). Their mode of action was established and consisted in the inhibition of protoporphyrinogen oxidase (PPO) the last enzyme at the branching point between heme and 
A

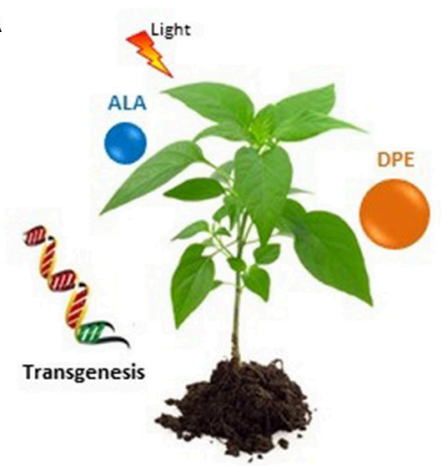

Uroporphyrins

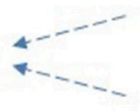

\section{Glutamate + tRNA \\ GluTS \\ Glutamyl t-RNA}

GluTR

Glutamate semialdehyde

ALAS $\downarrow$ GSA

5-Aminolevulinic acid (ALA)

PBS

Porphobilinogen

$\checkmark$ PBGD

Hydroxymethybilane

UROS

Uroporphyrinogen III $\longrightarrow$ Siroheme

UROD

Coproporphyrinogen III

CPO

- Protoporphyrinogen IX

\ PPO

' Protoporphyrin IX

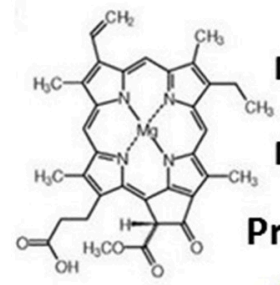

$\mathrm{MgCH}$

Mg-protoporphyrin IX

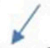

Mg-protoporphyrin IX ME

Protochlórophyllide ophyll
$\mathrm{FeCH}$

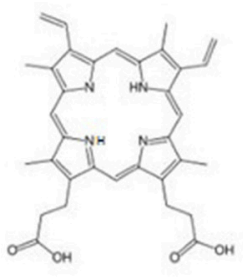

Fe-protoporphyrin IX

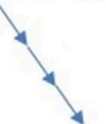

Heme

B

tpS

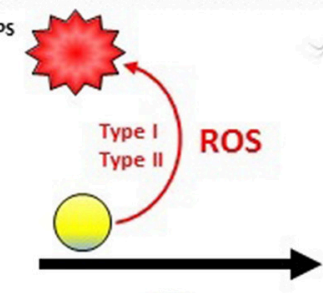

$\mathrm{O}_{2}$

Biomolecules
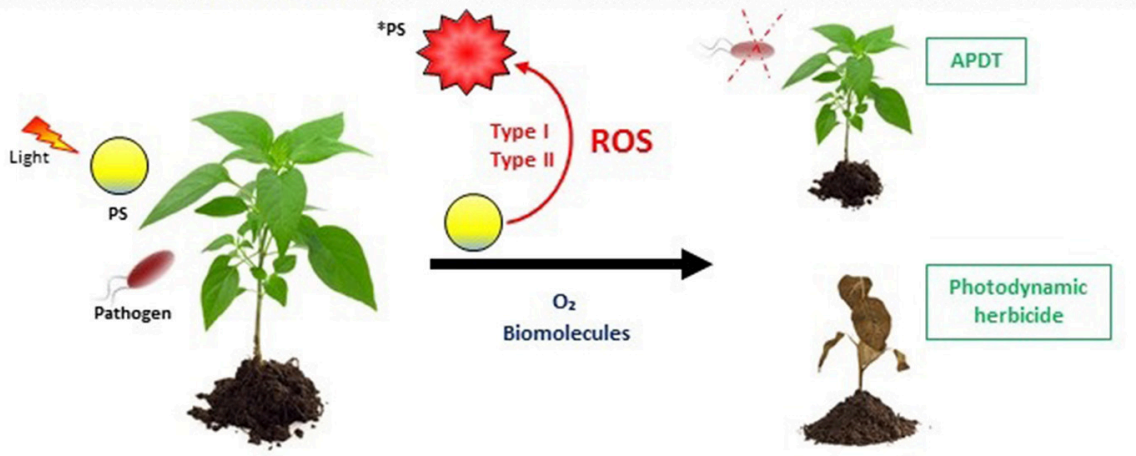

FIGURE 1 | Occurrence of plant photodynamic stress. (A) Indirect photodynamic stress occurs through forcing plants to over-accumulate endogenous PS upon tetrapyrrole biosynthetic pathway deregulation by ALA or DPE treatments as well as by transgenesis. Enzymes (capital letters) are shown in red. End products of the pathway are shown in green preceded by multi-arrows. Dashed arrows indicate the generation of endogenous PS (uroporphyrins, coproporphyrins, protoporphyrin IX that can be free-base or Fe/Mg metalated or esterified and protochlorophyllide) with the corresponding structures of the main harmful PS: protoporphyrin IX and protochlorophyllide. The non-plant enzyme ALAS is shown in gray. The first common precursor ALA is shown in blue with its chemical structure. ALAS,

5-aminolevulinic acid synthase; CPO, coproporphyrinogen oxidase; FeCH, Fe-chelatase; GSA, glutamate-1-semialdehyde aminotransferase; GlutTR, glutamyl-tRNA reductase; GluTS, glutamyl t-RNA synthetase; PBGD, porphobilinogen deaminase; MgCH, Mg-chelatase; Mg-protoporphyrin IX ME, Mg-protoporphyrin IX methyl ester; PPO, protoporphyrinogen oxidase; UROD, uroporphyrinogen decarboxylase; UROS, uroporphyrinogen synthase. (B) Direct photodynamic stress is carried out via the use of exogenous PS such as porphyrins, phenothiazinium dyes, coumarins, and furocoumarins leading to ROS generation via two types of photochemical reactions upon irradiation. It was recently investigated for applications in agronomy in the context of APDT and for new herbicide development. *PS, excited PS. 


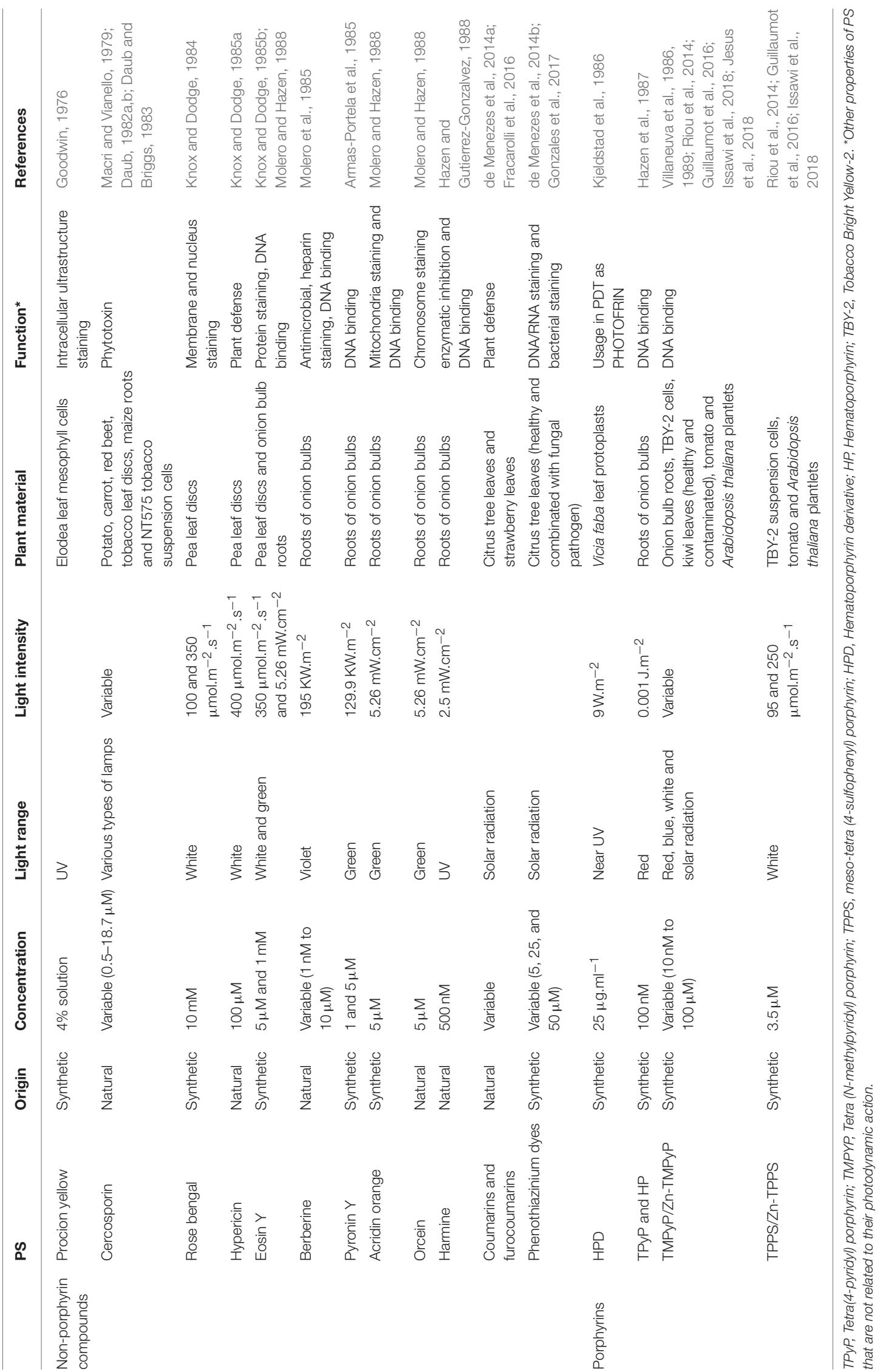


chlorophyll synthesis (Figure 1A; Matringe and Scalla, 1987; Matringe et al., 1989a,b). Thus, triggering leakage of PPO substrate, the non-fluorescent protoporphyrinogen IX that was converted by unknown peroxidase to the first effective PS of this pathway PPIX. Indeed, when PPIX absorbs light, it induces photochemical reactions and vital processes are affected (Figure 1A).

\section{DIRECT PHOTODYNAMIC STRESS: AN OLD STORY WITH NOVEL DEVELOPMENT}

Plant exposure to exogenous PS could induce tissue damage and subsequently cell death. First studies relative to direct application of PS on plant materials were reported four decades ago (Table 1). Concerning porphyrins, the most used PS, Kjeldstad and coworkers showed the photodamage of plasma membrane of Vicia faba leaf protoplasts subjected to hematoporphyrin derivative treatment under near UV light (Kjeldstad et al., 1986). Moreover, other studies showed mutagenic effect of porphyrins which were able to bind DNA in root meristematic cells of onion bulbs (Table 1; Villaneuva et al., 1986, 1989; Hazen et al., 1987). The aims of testing exogenous PS on plant materials were to study the symplastic intracellular movement, decipher the mode of action of fungal toxin as well as the effects of singlet oxygen on plant cells and exploring sister chromatide exchange upon dye DNA-intercalation in fast-rate dividing cells (Table 1; Goodwin, 1976; Macri and Vianello, 1979; Daub, 1982a,b; Daub and Briggs, 1983; Knox and Dodge, 1984, 1985a,b; Armas-Portela et al., 1985; Molero et al., 1985; Kjeldstad et al., 1986; Villaneuva et al., 1986, 1989; Hazen et al., 1987; Hazen and Gutierrez-Gonzalvez, 1988; Molero and Hazen, 1988).

For agronomic issues, the use of exogenous PS as powerful photoactivated molecules was not anymore investigated because the undesirable effects described above. Hence, any potential application of whatever PS in the aim to fight plant pathogens requires a risk assessment on plant hosts. It was reported that natural photosensitizers such as coumarins and furocoumarins or synthetic ones such as phenothiazinium and porphyrins inactivated pathogenic agents as virus (Tobacco mosaic virus), bacteria (Pseudomonas syringae) and fungi (Collectotrchum abscissum, Colletotrichum gloeosporioides, Collectotrichum acutatum, Aspergillus nidulans, Fusarium oxysporum, Fusarium moniliforme, Fusarium solani) (Table 1). However, when spotted on orange tree and strawberry plants, or on kiwi contaminated leaves under solar radiation, the leaves and flowers were not affected by either natural/synthetic photosensitizers excepted for strawberry leaves that were damaged upon treatment with $100 \mu \mathrm{M}$ phenothiazinium (Orlob, 1967; de Menezes et al., 2014a,b; Fracarolli et al., 2016; Gonzales et al., 2017; Jesus et al., 2018). In another extended context, Issawi and co-workers conceived a double target strategy that could eradicate in the same time unwanted vegetation and plant pathogens without killing plants of agronomic interest (Figure 1B). To fulfill that purpose, they studied the effect of exogenous watersoluble cationic and anionic porphyrins on tomato, plant of agronomic interest and on Arabidopsis thaliana, weed-like plant. Thus, they showed that cationic porphyrins were able to eradicate Arabidopsis plantlets without killing tomato plantlets (Guillaumot et al., 2016; Issawi et al., 2018). Favorably, Riou and co-workers treated TBY-2 cells with these same porphyrins aiming to find out new herbicides because no new herbicide modes of action were discovered since the last 3 decades (Duke, 2012; Heap, 2014; Riou et al., 2014).

\section{DETERMINANTS OF PLANT PHOTODYNAMIC STRESS}

Plants exposed to various stressors respond by involving mechanisms of sensing and signaling (Tuteja and Sopory, 2008; Mittler and Blumwald, 2010; Suzuki et al., 2012; Pandey et al., 2016; Zhu, 2016; Mittler, 2017). Although plant stress signaling pathways were abundantly investigated, stress sensors remain largely unknown so it is much difficult to detect sensing systems in plants subjected to direct photodynamic stress under unconventional conditions. However, Phung and collaborators outlined the switch photodynamic/droughttolerance in PPO-transgenic rice under drought conditions explaining how drought determinants reduced porphyrin level in order to elaborate tolerance response through gene expression modulation upon sensing change in tetrapyrrole amount (Phung et al., 2011). Nonetheless seeking for photodynamic sensors represents serious challenge. Exogenous PS exert photodynamic function through the production of ROS including singlet oxygen and hydrogen peroxide which are well known signaling molecules, it is worthwhile to distinguish between primary sensing that may be assigned to the PS per se and secondary sensing ascribed to ROS (Laloi et al., 2007; Niu and Liao, 2016; Wang et al., 2016). ABC transporters and TSPO receptor could play role in exogenous PS sensing since they were identified as endogenous tetrapyrrolic receptors (Theodoulou, 2000; Guillaumot et al., 2009). Interestingly, PPIX interacted with Toll-Like Receptor 4 (TLR-4) in mammals. Possible interaction with a putative TLR should be investigated in plant cells (Figueiredo et al., 2007; Tangudu and Spasic, 2017). In term of signaling, exogenous photodynamic action is likely to generate various secondary messengers holding signaling potential like ROS, modified proteins, lipid peroxidation byproducts. In addition, photodynamic signaling may also involve cross-talk with phytohormones as abscissic acid, jasmonic acid, salicylic acid, calcium, protein kinases, transcription factors (Tuteja and Sopory, 2008; Suzuki et al., 2012; Zhu, 2016). Thus, studies involving transcription profiling, proteomic and metabolomic approaches should be envisaged upon photodynamic administration of exogenous PS in plants.

\section{CHALLENGES AND PERSPECTIVES}

In the present review, two ways to carry out photodoynamic action on plants were emphasized (i) indirect photodynamic reaction via ALA or DPE treatments and transgenesis, (ii) direct photodynamic reaction through the use of exogenous PS. Comparing to conventional weed management methods using 
photodynamic DPE herbicides that are commercially available, it was reported that this kind of herbicides were not only toxic to weeds but wildlife was also affected as DPE herbicides were toxic to nestling birds and fresh water polyp, also, they could be toxic to humans. In addition, DPE alone were not expected to control weeds and need the combinational use of chemicals or mulch. Indeed, there are several reported weeds that developed DPEresistance (Hoffman et al., 1991; Rio et al., 1997; Li and Nicholl, 2005; Beckie and Tardif, 2012; Reed et al., 2018). Thus, we conclude that direct photodynamic treatment holding herbicidal potential via exogenous PS could be a promising approach relying on the fact that weeds cannot induce resistance against PS because they exert a multi-targeted photodynamic action damaging cellular DNA, lipids, carbohydrates and proteins. Taken together, we support the application of exogenous PS as weed control alternative and further studies are required as far as we know that studies concerning that task are very few (Riou et al., 2014; Issawi et al., 2018).

In regard to antimicrobial strategies, APDT was recently envisaged as promising approach to strike against plant pathogens without side effects on plant hosts and environment. In this context, we think that several aspects must be taken into consideration such as whole study of a defined pathosystem should be considered including biological life cycle of pathogen, growth and reproduction phenology of plants and timing of PS application. Moreover, PS administration methods as inclusion in soil aqueous phase, spotting on leaves and field spraying should not be neglected although spraying is the most convenient and reasonable.

\section{REFERENCES}

Almeida, A., Cunha, A., Faustino, M. A. F., Tome, A. C., and Neves, M. G. P. M. S. (2011). "Porphyrins as antimicrobial photosensitizing agents" in Photodynamic Inactivation of Microbial Pathogens: Medical and Environmental Applications, eds M. R. Hamblin and G. Jori (Cambridge, UK: RCS Publishing), 83-160.

Alves, E., Faustino, M. A. E., Neves, M. S., Cunhaa, A., Nadaisc, H., and Almeida, A. (2015). Potential applications of porphyrins in photodynamic inactivation beyond the medical scope. J. Photochem. Photobiol. B Biol. 22, 34-57. doi: 10.1016/j.jphotochemrev.2014.09.003

Armas-Portela, R., Hazen, M. J., and Stockert, J. C. (1985). Increase in sister-chromatid exchanges in BrdU-substituted chromosomes of Allium cepa induced by the combined effect of pyronin $\mathrm{Y}$ and green light. Mutat. Res. Genet. Toxicol. 158, 77-80. doi: 10.1016/0165-1218(85) 90100-4

Ayliffe, M. A., Agostino, A., Clarke, B. C., Furbank, R., Von Caemmerer, S., and Pryor, A. J. (2009). Suppression of the barley uroporphyrinogen III synthase gene by a Ds activation Tagging element generates developmental photosensitivity. Plant Cell 21, 814-831. doi: 10.1105/tpc.108. 063685

Battersby, A. R., Fooks, C. J. R., Matcham, G. W. H., and Mcdonald, E. (1980). Biosynthesis of the pigments of life: formation of the macrocycle. Nature 285, 17-21. doi: $10.1038 / 285017 \mathrm{a} 0$

Beckie, H. J., and Tardif, F. J. (2012). Herbicide cross resistance in weeds. Crop Prot. 35, 15-28. doi: 10.1016/j.cropro.2011.12.018

Ben Amor, T., and Jori, G. (2000). Sunlight-activated insecticides: historical background and mechanisms of phototoxic activity. Insect Biochem. Mol. Biol. 30, 915-925. doi: 10.1016/S0965-1748(00)00072-2

\section{CONCLUSION}

In conclusion, plant photodynamic stress is considered as abiotic stress linked to ROS production as the first cause of cell death. It is still poorly studied regarding characterization of photodynamic stress determinants and outcomes especially at molecular level in plants. Besides, plant photodynamic stress has not been exploited yet, especially as valuable exogenous treatment for the purposes we mentioned above. Nevertheless, we are confident that in the near future, this approach based on PS and especially porphyrins could be relevant to respond to the Directive 2009/128/EC of the European Parliament plans that aim to reduce the use of pesticides while maintaining high yield as well as high quality in agricultural production. PS are photodegradable and non-toxic under dark as well as they were used at micromolar concentrations therefore they could be promising candidates to fulfill the task of European projects for environment sustainability in respect to wildlife, water sources and human health.

\section{AUTHOR CONTRIBUTIONS}

MI and CR prepared and wrote the present manuscript. MI designed the figure and the table. VS reviewed the manuscript.

\section{ACKNOWLEDGMENTS}

MI was supported by a Grant from the Municipality of Sharkieh (Lebanon).

Brouillet, N., Arselin-De Chateaubodeau, G., and Volland, C. (1975). Studies on protoporphyrin biosynthetic pathway in Saccharomyces cerevisiae; characterization of the tetrapyrrole intermediates. Biochimie 57, 647-655. doi: 10.1016/S0300-9084(75) 80146-5

Chakradhar, T., Mahanty, S., Reddy, R. A., Divya, K., Reddy, P. S., and Reddy, M. K. (2017). "Biotechnological perspective of reactive oxygen species (ROS)-mediated stress tolerance in plants," in Reactive Oxygen Species and Antioxidant Systems in Plants: Role and Regulation under Abiotic Stress, eds M. Khan and N. Khan (Singapore: Springer), 53-87.

Daub, M. E. (1982a). Cercosporin, a photosensitizing toxin from Cercospora species. Phytopathology 72, 370-374. doi: 10.1094/Phyto-72-370

Daub, M. E. (1982b). Peroxidation of tobacco membrane lipids by the photosensitizing toxin, cercosporin. Plant Physiol. 69, 1361-1364. doi: 10.1104/pp.69.6.1361

Daub, M. E., and Briggs, S. P. (1983). Changes in tobacco cell membrane composition and structure caused by cercosporin. Plant Physiol. 71, 763-766. doi: 10.1104/pp.71.4.763

de Menezes, H. D., Pereira, A. C., Brancini, G. T. P., Leão, H. C., Massola Júnior, N. S., Bachmann, L., et al. (2014a). Furocoumarins and coumarins photoinactivate Colletotrichum acutatum and Aspergillus nidulans fungi under solar radiation. J. Photochem. Photobiol. Biol. 131, 74-83. doi: 10.1016/j.jphotobiol.2014. 01.008

de Menezes, H. D., Rodrigues, G. B., Teixeira, S. P., Massola, N. S., Bachmann, L., Wainwright, M., et al. (2014b). In vitro photodynamic inactivation of plantpathogenic fungi colletotrichum acutatum and colletotrichum gloeosporioides with novel phenothiazinium photosensitizers. Appl. Environ. Microbiol. 80, 1623-1632. doi: 10.1128/AEM.02788-13 
Donnelly, R. F., McCarron, P. A., and Tunney, M. M. (2008). Antifungal photodynamic therapy. Microbiol. Res. 163, 1-12. doi: 10.1016/j.micres.2007.08.001

Duke, S. O. (2012). Why have no new herbicide modes of action appeared in recent years? Pest Manag. Sci. 68, 505-512. doi: 10.1002/ps.2333

Figueiredo, R. T., Fernandez, P. L., Mourao-Sa, D. S., Porto, B. N., Dutra, F. F., Leticia, L. S., et al. (2007). Characterization of heme as activator of toll-like receptor 4. J. Biol. Chem. 282, 20221-20229. doi: 10.1074/jbc.M610737200

Fotinos, N., Campo, M. A., Popowycz, F., Gurny, R., and Lange, N. (2006). 5-Aminolevulinic acid derivatives in photomedicine: characteristics, application and perspectives. J. Photochem. Photobiol. 82, 994-1015. doi: 10.1562/2006-02-03-IR-794

Foyer, C. H., Lelandais, M., and Kunert, K. J., (1994). Photooxidative stress in plants. Physiol. Plant 92, 696-717. doi: 10.1111/j.1399-3054.1994.tb03042.x

Fracarolli, L., Rodrigues, G. B., Pereira, A. C., Massola Júnior, N. S., Silva-Junior, G. J., Bachmann, L., et al. (2016). Inactivation of plantpathogenic fungus Colletotrichum acutatum with natural plant-produced photosensitizers under solar radiation. J. Photochem. Photobiol. Biol. 162, 402-411. doi: 10.1016/j.jphotobiol.2016.07.009

Gonzales, J. C., Brancini, G. T. P., Rodrigues, G. B., Silva-Junior, G. J., Bachmann, L., Wainwright, M., et al. (2017). Photodynamic inactivation of conidia of the fungus Colletotrichum abscissum on Citrus sinensis plants with methylene blue under solar radiation. J. Photochem. Photobiol. Biol. 176, 54-61. doi: 10.1016/j.jphotobiol.2017.09.008

Goodwin, P. B. (1976). "Physiological and electrophysiological evidence for intercellular communication in plant symplasts," in intercellular Communication in Plants: Studies on Plasmodesmata, eds B. E. S. Gunning and A. W. Robards (Berlin; Heidelberg; New York, NY: Springer), 121-129. doi: 10.1007/978-3-642-66294-2_6

Guillaumot, D., Guillon, S., Morsomme, P., and Batoko, H. (2009). ABA, porphyrins and plant TSPO-related protein. Plant Signal. Behav. 4, 1087-1090. doi: $10.4161 /$ psb.4.11.9796

Guillaumot, D., Issawi, M., Da Silva, A., Leroy-Lhez, S., Sol, V., and Riou, C. (2016). Synergistic enhancement of tolerance mechanisms in response to photoactivation of cationic tetra ( $\mathrm{N}$-methylpyridyl) porphyrins in tomato plantlets. J. Photochem. Photobiol. Biol. 156, 69-78. doi: 10.1016/j.jphotobiol.2016.01.015

Hamblin, M. R. (2016). Antimicrobial photodynamic inactivation: a bright newtechnique to kill resistant microbes. Curr. Opin. Microbiol. 33, 67-73. doi: 10.1016/j.mib.2016.06.008

Hasan, M. K., Cheng, Y., Kanwar, M. K., Chu, X. Y., Ahammed, G. J., and Qi, Z. Y. (2017). Responses of plant proteins to heavy metal stress-a review. Front. Plant Sci. 8:1492. doi: 10.3389/fpls.2017.01492

Hazen, M. J., and Gutierrez-Gonzalvez, M. G. (1988). UV-mediated toxic bioactivity of harmine in the meristematic cells of Allium cepa. Mutagenesis 3, 333-335. doi: 10.1093/mutage/3.4.333

Hazen, M. J., Villaneuva, A., and Stockert, J. C. (1987). Induction of sister chromatide echanges in Allium cepa meristematic cells exposed to mesotetra (4-pyridyl) porphine and hematoporphyrin photoradiation. J. Photochem. Photobiol. Biol. 46, 463-467. doi: 10.1111/j.1751-1097.1987.tb04796.x

Heap, I. (2014). Global perspective of herbicide-resistant weeds. Pest Manag. Sci. 70, 1306-1315. doi: 10.1002/ps.3696

Hoffman, D. J., Spann, J. W., LeCaptain, L. J., Christine, M. B., and Rattner, B. A. (1991). Developmental toxicity of diphenyl ether herbicides in nestling American kestrels. J. Toxicol. Environ. Health 34, 323-336. doi: $10.1080 / 15287399109531571$

Hu, B., Wang, W., Deng, K., Li, H., Zhang, Z., Zhang, L., et al. (2015). MicroRNA399 is involved in multiple nutrient starvation responses in rice. Front. Plant Sci. 6:188. doi: 10.3389/fpls.2015.00188

Issawi, M., Guillaumot, D., Sol, V., and Riou, C. (2018). Responses of an adventitious fast-growing plant to photodynamic stress: comparative study of anionic and cationic porphyrin effect on Arabidopsis thaliana. Physiol. Plant 162, 379-390. doi: 10.1111/ppl.12666

Jaleel, C. A., Manivannan, P., Wahid, A., Farooq, M., Al-juburi, H. J., Somasundaram, R., et al. (2017). Drought stress in plants: a review on morphological characteristics and pigments composition. Int. J. Agric. Biol. 11, 100-105.
Jesus, V., Martins, D., Branco, T., Valério, N., Neves, M. G. P. M. S., Faustino, M. A. F., et al. (2018). An insight into the photodynamic approach versus copper formulations in the control of Pseudomonas syringae pv. actinidiae in kiwi plants. Photochem. Photobiol. Sci. 17, 180-191. doi: 10.1039/C7PP00300E

Jori, G. (2011). "Antimicrobial photodynamic therapy: basic principles," in Photodynamic Inactivation of Microbial Pathogens: Medical and Environemental Applications, eds M. R. Hamblin and G. Gori (Cambridge, UK: RCS Publishing), 83-160.

Jori, G., and Brown, S. (2004). Photosensitized inactivation of microorganisms. Photochem. Photobiol. Sci. 3, 403-405. doi: 10.1039/b311904c

Jung, S. (2011). Level of protoporphyrinogen oxidase activity tightly correlates with photodynamic and defense responses in oxyfluorfen-treated transgenic rice. $J$. Pestic. Sci. 36, 16-21. doi: 10.1584/jpestics.G10-46

Jung, S., Lee, H. J., Lee, Y., Kang, K., Kim, Y. S., Grimm, B., et al. (2008). Toxic tetrapyrrole accumulation in protoporphyrinogen IX oxidaseoverexpressing transgenic rice plants. Plant Mol. Biol. 67, 535-546. doi: 10.1007/s11103-008-9338-0

Jung, S., Yang, K., Lee, D. E., and Back, K. (2004). Expression of Bradyrhizobium japonicum 5-aminolevulinic acid synthase induces severe photodynamic damage in transgenic rice. Plant Sci. 167, 789-795. doi: 10.1016/j.plantsci.2004.05.038

Juzeniene, A., Juzenas, P., Iani, V., and Moan, J. (2002). Topical application of 5 aminolevulinic acid and its methylester, hexylester and octylester derivatives: considerations for dosimetry in mouse skin model. J. Photochem. Photobiol. 76, 329-334. doi: 10.1562/0031-8655(2002)076<0329:TAOAAA $>2.0$.CO;2

Kashef, N., Huang, Y. Y., and Hamblin, M. R. (2017). Advances in antimicrobial photodynamic inactivation at the nanoscale. Nanophotonics 6, 853-879. doi: 10.1515/nanoph-2016-0189

Kim, J. G., Back, K., Lee, H. Y., Lee, H. J., Phung, T. H., Grimm, B., et al. (2014). Increased expression of Fe-chelatase leads to increased metabolic flux into heme and confers protection against photodynamically induced oxidative stress. Plant Mol. Biol. 6, 271-287. doi: 10.1007/s11103-0140228-3

Kjeldstad, B., Olsten, M. L., Christensen, T., and Johnsson, A. (1986). Photodynamic damage to protoplasts with a hematoporphyrin derivative. Plant Sci. 44, 139-143. doi: 10.1016/0168-9452(86)90083-X

Knox, J. P., and Dodge, A. D. (1984). Photodynamic damage to plant leaf tissue by rose bengal. Plant Sci. Lett. 37, 3-7. doi: 10.1016/0304-4211(84)90194-9

Knox, J. P., and Dodge, A. D. (1985a). Isolation and activity of the photodynamic pigment hypericin. Plant Cell Environ. 8, 19-25. doi: 10.1111/j.1365-3040.1985.tb01204.x

Knox, J. P., and Dodge, A. D. (1985b). The photodynamic action of eosin, a singlet-oxygen generator. Planta 164, 22-29. doi: 10.1007/BF00391021

Laloi, C., Stachowiak, M., Pers-Kamczyc, E., Warzych, E., Murgia, I., and Apel, K. (2007). Cross-talk between singlet oxygen- and hydrogen peroxide-dependent signaling of stress responses in Arabidopsis thaliana. Proc. Natl. Acad. Sci. U.S.A. 104, 672-677. doi: 10.1073/pnas.0609063103

Lee, Y., Jung, S., and Back, K. (2004). Expression of human protoporphyrinogen oxidase in transgenic rice induces both a photodynamic response and oxyfluorfen resistance. Pest. Biochem. Physiol. 80, 65-74. doi: 10.1016/j.pestbp.2004.06.008

$\mathrm{Li}, \mathrm{X}$. (2003). Development of protoporphyrinogen oxidase as an efficient selection marker for agrobacterium tumefaciens-mediated transformation of maize. Plant Physiol. 133, 736-747. doi: 10.1104/pp.103.026245

Li, X., and Nicholl, D. (2005). Development of PPO inhibitor-resistant cultures and crops. Pest Manag. Sci. 61, 277-285. doi: 10.1002/ps.1011

Liu, Y., Qin, R., Zaat, S., Breukink, E., and Heger, M. (2015). Antibacterial photodynamic therapy: overview of a promising approach to fight antibiotic-resistant bacterial infections. J. Clin. Transl. Res. 1, 140-167. doi: $10.18053 /$ jctres.201503.002

Loreti, E., Van veen, H., and Perata, P. (2016). Plant responses to flooding stress. Curr. Opin. Plant Biol. 33, 64-71. doi: 10.1016/j.pbi.2016. 06.005

Macri, F., and Vianello, A. (1979). Photodynamic activity of cercosporin on plant tissues. Plant Cell Environ. 2, 267-271. doi: 10.1111/j.1365-3040.1979.tb00078.x

Maisch, T. (2007). Anti-microbial photodynamic therapy: useful in the future? Lasers Med. Sci. 22, 83-91. doi: 10.1007/s10103-006-0409-7 
Maisch, T. (2009). A new strategy to destroy antibiotic resistant microorganisms: antimicrobial photodynamic treatment. Mini Rev. Med. Chem. 9, 974-983. doi: $10.2174 / 138955709788681582$

Matringe, M., Camadro, J., Labbe, P., and Scalla, R. (1989a). Protoporphyrinogen oxidase as a molecular target for diphenyl ether herbicides. Biochem. J. 260, 231-235. doi: 10.1042/bj2600231

Matringe, M., Camadro, J., Labbe, P., and Scalla, R. (1989b). Protoporphyrinogen oxidase inhibition by three peroxidizing herbicides: oxadiazon, LS 82-556 and M\&B 39279. FEB Lett. 245, 35-38. doi: 10.1016/0014-5793(89)80186-3

Matringe, M., and Scalla, R. (1987). Photoreceptors and respiratory electron flow involvement in the activity of acifluorfen-methyl and LS 82-556 on non chlorophyllous soybean cells. Pest. Biochem. Physiol. 27, 267-274. doi: 10.1016/0048-3575(87)90056-3

Matsumoto, H., Tanida, Y., and Ishizuka, K. (1994). Porphyrin intermediate involved in herbicidal action of -Aminolevulinic acid on duckweed (Lemna paucicostata Hegelm.). Pest. Biochem. Physiol. 48, 214-221. doi: $10.1006 /$ pest.1994.1022

Mittler, R. (2017). ROS are good. Trends Plant Sci. 22, 11-19. doi: 10.1016/j.tplants.2016.08.002

Mittler, R., and Blumwald, E. (2010). Genetic engineering for modern agriculture: challenges and perspectives. Annu. Rev. Plant Biol. 61, 443-462. doi: 10.1146/annurev-arplant-042809-112116

Molero, M. L., and Hazen, M. J. (1988). Photodynamic effect of acridine orange, eosin $\mathrm{Y}$ and orcein in a plant system in vivo measured by the sister chromatid exchanges test. J. Plant Physiol. 132, 636-637. doi: 10.1016/S0176-1617(88)80268-2

Molero, M. L., Hazen, M. J., and Stockert, J. C. (1985). Photodynamic effect of berberine sulfate on the growth rate of Allium cepa roots. J. Plant Physiol. 120, 91-94. doi: 10.1016/S0176-1617(85)80126-7

Müller-Xing, R., Xing, Q., and Goodrich, J. (2014). Footprints of the sun: memory of UV and light stress in plants. Front. Plant Sci. 5:474. doi: $10.3389 /$ fpls.2014.00474

Nguyen, A. H., Kim, H.-S., and Jung, S. (2016). Altered tetrapyrrole metabolism and transcriptome during growth-promoting actions in rice plants treated with 5-aminolevulinic acid. Plant Growth Regul. 78, 133-146. doi: $10.1007 /$ s10725-015-0080-8

Niu, L., and Liao, W. (2016). Hydrogen peroxide signaling in plant development and abiotic responses: crosstalk with nitric oxide and calcium. Front. Plant Sci. 7:230. doi: 10.3389/fpls.2016.00230

Ohama, N., Sato, H., Shinozaki, K., and Yamaguchi-Shinozaki, K. (2017). Transcriptional regulatory network of plant heat stress response. Trends Plant Sci. 22, 53-65. doi: 10.1016/j.tplants.2016.08.015

Orlob, G. B., (1967). Inactivation of purified plant viruses and their nucleic acids by photosensitizing dyes. Virol. J. 31, 402-413. doi: 10.1016/0042-6822(67)90219-X

Pandey, G. K., Pandey, A., Prasad, M., and Böhmer, M. (2016). Editorial: abiotic stress signaling in plants: functional genomic intervention. Front. Plant Sci. 7:681. doi: 10.3389/fpls.2016.00681

Phung, T. H., Jung, H. I., Park, J. H., Kim, J. G., Back, K., and Jung, S. (2011). Porphyrin biosynthesis control under water stress: sustained porphyrin status correlates with drought tolerance in transgenic rice. Plant Physiol. 157, 1746-1764. doi: 10.1104/pp.111.188276

Phung, T. H., and Jung, S. (2014). Perturbed porphyrin biosynthesis contributes to differential herbicidal symptoms in photodynamically stressed rice (Oryza sativa) treated with 5-aminolevulinic acid and oxyfluorfen. Pest. Biochem. Physiol. 116, 103-110. doi: 10.1016/j.pestbp.2014.10.002

Phung, T. H., and Jung, S. (2015). Differential antioxidant defense and detoxification mechanisms in photodynamically stressed rice plants treated with the deregulators of porphyrin biosynthesis, 5-aminolevulinic acid and oxyfluorfen. Biochem. Biophys. Res. Commun. 459, 346-351. doi: 10.1016/j.bbrc.2015.02.125

Pospísil, P. (2016). Production of reactive oxygen species by photosystem II as a response to light and temperature stress. Front. Plant Sci. 7:1950. doi: 10.3389/fpls.2016.01950

Quesada, V., Sarmiento-Manus, R., Gonzalez-Bayon, R., Hricova, A., Ponce, M. R., and Micol, J. L. (2013). Porphobilinogen deaminase deficiency alters vegetative and reproductive development and causes lesions in Arabidopsis. PLoS ONE 8:53378. doi: 10.1371/journal.pone.0053378
Ramel, F., Sulmon, C., Serra, A. A., Gouesbet, G., and Couée, I. (2012). Xenobiotic sensing and signalling in higher plants. J. Exp. Bot. 63, 3999-4014. doi: $10.1093 /$ jxb/ers102

Rebeiz, C. A. (2014). Chlorophyll Biosynthesis and Technological Applications. Dordrecht; Heidelberg; New York, NY; London: Springer. doi: 10.1007/978-94-007-7134-5

Rebeiz, C. A., Gut, L. J., Lee, K., Juvik, J. A., Rebeiz, C. C., and Bouton, C. E. E. (1995). Photodynamics of porphyric insecticides. Crit. Rev. Plant Sci. 14, 329-366. doi: 10.1080/07352689509382363

Rebeiz, C. A., Montazer-Zouhoor, A., Hopen, H. J., and Wu, S. M. (1984). Photodynamic herbicides: 1. concept and phenomenology. Enzyme Microb. Technol. 6, 390-396. doi: 10.1016/0141-0229(84)90012-7

Rebeiz, C. A., Montazer-Zouhoor, A., Mayasich, J. M., Tripathy, B. C., Wu, S., Rebeiz, C. C., et al. (1988). Photodynamic herbicides. Recent developments and molecular basis of selectivity. Crit. Rev. Plant Sci. 6, 385-436. doi: 10.1080/07352688809382256

Rebeiz, C. A., Reddy, K. N., Nandihalli, U. B., and Velu, J. (1990). Tetrapyrroledependent photodynamic herbicides. Photochem. Photobiol. Sci. 52, 1099-1117. doi: 10.1111/j.1751-1097.1990.tb08451.x

Reed, T. V., Boyd, N. S., Wilson, P. C., and Dittmar, P. J. (2018). Effect of plastic mulch type on fomesafen dissipation in florida vegetable production systems. Weed Sci. 66, 142-148. doi: 10.1017/wsc.2017.48

Rihan, H. Z., Al-Issawi, M., and Fuller, M. P. (2017). Advances in physiological and molecular aspects of plant cold tolerance. J. Plant Interact. 12, 143-157. doi: 10.1080/17429145.2017.1308568

Rio, B., Parent-Massin, D., Lautraite, S., and Hoellinger, H. (1997). Effects of a diphenyl-ether herbicide, oxyfluorfen, on human BFU-E/CFU-E development and haemoglobin synthesis. Hum. Exp. Toxicol. 16, 115-122. doi: 10.1177/096032719701600207

Riou, C., Calliste, C. A., Da Silva, A., Guillaumot, D., Rezazgui, O., Sol, V., et al. (2014). Anionic porphyrin as a new powerful cell death inducer of Tobacco Bright Yellow-2 cells. Photochem. Photobiol. Sci. 13, 621-625. doi: $10.1039 /$ c3pp50315a

Sasikala, C. H., Ramana, C. V., and Rao, P. R. (1994). 5-Aminolevulinic acid: a potential herbicide/insecticide from microorganisms. Biotechnol. Prog. 10, 451-459. doi: 10.1021/bp00029a001

Senge, M. O., MacGowan, S. A., and O’Brien, J. M. (2015). Conformational control of cofactors in nature - the influence of protein-induced macrocycle distortion on the biological function of tetrapyrroles. ChemComm 51, 17031-17063. doi: 10.1039/C5CC06254C

Senge, M., Ryan, A., Letchford, K., MacGowan, S., and Mielke, T. (2014). Chlorophylls, symmetry, chirality, and photosynthesis. Symmetry (Basel). 6, 781-843. doi: 10.3390/sym6030781

Suzuki, N., Koussevitzky, S., Mittler, R., and Miller, G. (2012). ROS and redox signaling in the response of plants to abiotic stress: ROS and redox signaling in plants. Plant Cell Environ. 35, 259-270. doi: 10.1111/j.1365-3040.2011.02336.x

Tangudu, N. K., and Spasic, M. V. (2017). Heme activates macrophage hepcidin expression via toll like receptor 4 and extracellular signalregulated kinases signaling pathway. J. Clin. Pharmacol. Biopharm. 6, 1-6. doi: 10.4172/2167-065X.1000166

Theodoulou, F. L. (2000). Plant ABC transporters. Biochim. Biophys. Acta 1465, 79-103. doi: 10.1016/S0005-2736(00)00132-2

Tim, M. (2015). Strategies to optimize photosensitizers for photodynamic inactivation of bacteria. J. Photochem. Photobiol. Biol. 150, 2-10. doi: 10.1016/j.jphotobiol.2015.05.010

Tuteja, N., and Sopory, S. K. (2008). Chemical signaling under abiotic stress environment in plants. Plant Signal. Behav. 3, 525-536. doi: $10.4161 /$ psb.3.8.6186

Vian, A., Davies, E., Gendraud, M., and Bonnet, P. (2016). Plant responses to high frequency electromagnetic fields. Biomed Res. Int. 2016:1830262. doi: $10.1155 / 2016 / 1830262$

Villaneuva, A., Hazen, M. J., and Stockert, J. C. (1986). Photodynamic effect of porphyrin derivative meso-tetra (4-N-methypyridyl) porphine on sister chromatide exchanges in meristematic cells. Experientia 42, 1269-1271. doi: 10.1007/BF01946418

Villaneuva, A., canete, M., and Hazen, M. J. (1989). Uptake and DNA photodamage induced in plant cells in vivo by two cationic porphyrins. Mutagenesis 4, 157-159. doi: 10.1093/mutage/4.2.157 
Wainwright, M., Maisch, T., Nonell, S., Plaetzer, K., Almeida, A., Tegos, G. P., et al. (2016). Photoantimicrobials-are we afraid of the light? Lancet Infect. Dis. 17, 49-55. doi: 10.1016/S1473-3099(16)30268-7

Wang, L., Kim, C., Xu, X., Piscurewiscz, U., Dogra, V., Singh, S., et al. (2016). Singlet oxygen- and EXECUTER1-mediated signaling is initiated in grana margins and depends on the protease FtsH2. Proc. Natl. Acad. Sci. U.S.A. 113, 1-9. doi: 10.1073/pnas. 1603562113

Xu, L., Zhang, W., Ali, B., Islam, F., Zhu, J., and Zhou, W. (2015). Synergism of herbicide toxicity by 5 -aminolevulinic acid is related to physiological and ultrastructural disorders in crickweed (Malachium aquaticum L.). Pest. Biochem. Physiol. 125, 53-61. doi: 10.1016/j.pestbp.2015.06.002

Yang, K., Jung, S., Lee, Y., and Back, K. (2006). Modifying Myxococcus xanthus protoporphyrinogen oxidase to plant codon usage and high level of oxyfluorfen resistance in transgenic rice. Pest. Biochem. Physiol. 86, 186-194. doi: 10.1016/j.pestbp.2006.04.003

Yang, Y., and Guo, Y. (2017). Elucidating the molecular mechanisms mediating plant salt-stress responses. New Phytol. 2, 523-539. doi: 10.1111/nph.14920
Yun, Y. B., Park, J. I., Choi, H. S., Jung, H., Jang, S. J., Back, K., et al (2013). Protoporphyrinogen oxidase-overexpressing transgenic rice is resistant to drought stress. Crop Sci. 53, 1076-1085. doi: 10.2135/cropsci2012. 07.0452

Zhu, J. K. (2016). Abiotic stress signaling and responses in plants. Cell 167, 313-324. doi: 10.1016/j.cell.2016.08.029

Conflict of Interest Statement: The authors declare that the research was conducted in the absence of any commercial or financial relationships that could be construed as a potential conflict of interest.

Copyright $\odot 2018$ Issawi, Sol and Riou. This is an open-access article distributed under the terms of the Creative Commons Attribution License (CC BY). The use, distribution or reproduction in other forums is permitted, provided the original author(s) and the copyright owner are credited and that the original publication in this journal is cited, in accordance with accepted academic practice. No use, distribution or reproduction is permitted which does not comply with these terms. 